\title{
Pharmacological and Non-pharmacological Treatment for Improved Sexual Function
}

Medical treatments are available to treat patients [1]. These include tablets that increase the flow of blood into a penis causing an erection, sufficient for intercourse. Should these fail, intraurethral and intracavernosal devices are available. Should these also not work, there are mechanical treatment options e.g. penile prosthesis are available with high success rates [2]. Quality of life, wellbeing and mental health are further supported by successes in these treatments. However, what has also been highlighted is lack of patient assessment for erectile dysfunction as part of the 'usual' post-operative care pathway [3,4].

\section{References}

1. Rajendran R, Cummings M. Erectile dysfunction: assessment and management in primary care. Prescriber. 2014;25:25-30.

2. Akbal C, Tinay I, Simsek F, Turkeri LN. Erectile dysfunction following radiotherapy and brachytherapy for prostate cancer: pathophysiology, prevention and treatment. Int Urol Nephrol. 2008;40:355-63.

3. Kirby CN, Piterman L, Giles C. GP management of erectile dysfunction: the impact of clinical audit and guidelines. Aust Fam Physician. 2009;38:637-41.

4. Rutherford D. Erectile dysfunction: assessment, treatment and prescribing issues. Nurs Times. 2002;98:30-3. 